\title{
SONHOS INFANTIS E CONDUTA FAMILIAR
}

\author{
GONCALVES FERNANDES *
}

A despistagem precoce de erros educacionais domésticos constituiria, para o educador, um rápido avanço na prevenção de desajustamentos, máxime na fase de fixação do estilo de vida, quando mais ponderável se torna o comportamento parental para a conduta futura da criança. A distensão do processo educativo da escola ao lar, tornando-a uma célula de educação integral, por que se bate a Secção de Ortofrenia e Higiene Mental do D.S.P., não apenas no tratamento, de crianças-problemas, mas no que se possa fazer para melhorar as condições gerais de correto ajustamento de tôdas elas, permite realizar operações de assistência às normas educacionais domésticas e até mesmo tentativas de reeducação familiar.

Partindo destas premissas, procuramos observar em alunos dos jardins de infância, mesmo aqueles que não apresentavam problemas de conduta ou de escolaridade, os reflexos do comportamento parental na formação do seu estilo de vida. Acreditamos que a análise de sonhos e de fantasias infantis, material que comumente não é coligido pelo educador, poderia permitir um reconhecimento de como se está processando o estilo de vida da criança, a ação parental, os conflitos familiares e os erros de atitude diante da criança, favorecendo uma intervenção precoce nas famílias socialmente operáveis e uma participação corretiva oportuna.

$\mathrm{Na}$ primeira e segunda infância dificilmente se poderia distinguir o real do imaginário em função da sua existência objetiva, espacial, mas já não se duvida de que as criações da fantasia sejam ditadas pelo estilo de vida. Assim, ensaiamos uma sondagem sôbre a formação do estilo de vida entre alunos dos jardins de infancia do Recife, através da análise de sonhos e de histórias "inventadas". Todo o material foi colhido de crianças normais, de 4 a 7 anos de idade, em jardins de infância das escolas públicas. Foram, assim, abordadas 177 crianças, das quais 61 contaram sonhos, uma contou um sonho e uma história, 92 contaram histórias e 23 se recusaram às várias tentativas neste sentido.

Trabalho da Secção de Ortoírenia e Higiene Mental (Pernambuco). Pesquisas realizadas com a cooperação das auxiliares Carmen Cavalcanti, Gilka Lemos Gibson e Elisabete Barros Lima.

* Docente-livre de Clínica Psiquiátrica na Escola de Medicina e Cirurgia do Rio de do Estado de Pernambuco. 
Quase tôdas as histórias colhidas não são mais do que o aproveitamento temático-individual, por parte da criança, de contos infantis mais ou menos conhecidos, alguns do domínio folclórico, se bem que em versão de colorido pessoal. A análise extensiva, a grosso modo, do material colhido revela a freqüência de alvos de superioridade a atingir, outros de supercompensação afetiva, com rasgos de valoração dramática. Os sonhos relatados, entretanto, constituíram um material surpreendente, refletindo, na sua maioria, muito mais do que as histórias, pelo seu conteúdo, flagrantes expressivos de mêdo, temor, perigo, limite de expansão dos impulsos genuínos, situações de incompletude e angústia, exteriorização simbólica de suas vivências em face dos pais, irmãos, familiares, vizinhos, educadores e colegas do seu grupo social, com suas dificuldades e deficiências educacionais, necessidades e inquietude temporal.

Cinco crianças perfeitamente ajustadas relataram sonhos que são instantâneos da sua vida escolar diária, sonhos "realizados", quase sem linguagem cifrada (Fichas 86, 107, 43, 65, 10). Tôdas têm irmãos e brincam entre si e com os meninos vizinhos de mesma condição social. Sete outras, em igualdade de ajustamento, contaram sonhos também "realizados", passeios em companhia dos pais, refeições feitas em sua companhia ou ainda, simplesmente, com os pais dentro de casa, sem referências particulares em relação a qualquer um dêles, imagens rápidas da vida doméstica diária, com simbolismo elementar de projeção normal de evolução de sentimentos (Fichas 84, 6, 55, $153,74,70,66)$.

Seis crianças não perfeitamente ajustadas nas suas relações de vizinhança, pertencentes a famílias relativamente abastadas à vista do seu círculo residencial (moram em boas casas situadas em ruas de residências humildes) e cujos pais proibem sua aproximação com as outras vizinhas, contaram sonhos com simbolismo de perda e valoração compensativa de protótipo, outros de angústia, ameaça ou expectativa de perda e dois últimos de contraste valorativo ante o temor:

Sonho - real e recente: "Eu sonhci com um ladräo que cstaza correndo $e$ ıma porção de gente para pegar o ladrão $e$ dois guardas $e$ o pessoal pegou o ladrão e botou êle no quartel". M. L. de H. C., 5 anos, sexo masculino, leucodermo, aluno do jardim de infância do Grupo J. Barbalho. Sua família é relativamente abastada e mora à rua Martins Junior. Seu pai é industriário e sua mãe cuida da casa. Tem um irmão mais velho, de 7 anos, e dois mais moços, um de 3 anos e uma de 2 anos. $O$ paciente não brinca com os meninos da vizinhança porque os pais não deixam (Ficha 93).

Sonho - real e recente: "Eu só sonho quando estou... eu sonhei que um homem tinha uma máscara de bigode e corri para casa e tinha medo e mandava papai matar êle e êle matava êle (ao ladrão)". F. Am. M. P. F., 4 anos, sexo masculino, leucodermo, aluno do J. de I. do Grupo J. Barbalho. Seu pai é funcio- 
nario público e sua mãe cuida da casa. Sua família é de condição social médìa e reside à rua dos Palmares. Tem três irmãos mais velhos. Em relação à vizinhança disse: "Eu sou mais rico, todo mundo lá em casa é rico". Não brinca com os meninos da vizinhança (Ficha 110).

Sonho: "Eu sonhei com um ladrão em cima da casa". G. P., 6 anos, sexo masculino, leucodermo, aluno do J. d. I. do Grupo A. de Medeiros. Seu pai é marceneiro e sua mãe visitadora. Família de condição social modesta mas melhor provida do que a dos vizinhos, e reside à rua Figueiredo. Tem dois irmãos e duas irmãs, todos mais velhos do que o paciente. Não lhe é permitido pela sua família brincar com os vizinhos ou na rua (Ficha 39).

Sonho: "Eu sonhei com um ladrão que tinha roubado um z'elocípede meu... $V i$ uma alma tôda de branco, mais nada". N. de A. M., 5 anos, sexo masculino, leucodermo, aluno do J d. I. do Grupo J. Barbalho. Seus pais trabalham em escritório industrial em Paulista. Sua família é modesta mas melhor provida do que as da vizinhança. Reside à rua dos Pires. Tem uma irmã mais velha, de 8 anos. Não brinca com os meninos da vizinhança (Ficha 105).

Sonho - real: "Um ladrão chegou ... não foi um ladrão não... era um homem batendo na porta... minha casa é um bangalô... só isso". A. S. S. B., 6 anos, sexo masculino, leucodermo, aluno do J. d. I. do Inst. Pedagógico. Seu pai é despachante e sua mãe cuida da casa. Tem três irmãos mais velhos e três irmãs também mais velhas, e uma irmã mais moça. Mora à rua Sta. Isabel. O paciente diz que as casas dos vizinhos são tôdas feias. Nenhum contacto com a vizinhança (Ficha 87).

Sonho: "Sonhei com um surrupcio que ia para debaixo do guarda-roupa... ai me deitei na cama alta $e .$. matava o surrupeio com a foice". P. de A. C., 4 anos, sexo masculino, leucodermo, aluno do J. d. I. do Inst. Pedagógico. Seu pai é pedreiro e sua mãe costureira. Tem cinco irmãos mais velhos e uma irmã mais moça. Sua família é de condição social modesta e mora no Córrego do Bartolomeu. Os vizinhos são de condição econômica inferior. Ausência de contacta com os meninos da vizinhança (Ficha 85).

Quatro crianças mimadas, que são objeto de atenções especiais por parte de seus familiares e que, por circunstâncias ocasionais, se viram afastadas dos mesmos, contaram sonhos em tôrno dêsses parentes, envolvendo situações afetivas de compensação por ausência:

Sonho - real e recente: "Eu estava em casa da minha avó.. minha avó doente $c$ aí cu estava na cama dela... eu fiquei doente também... minha avó não sabe onde eu estou e mandava os meninos me procurar para me achar... me acharam $e$ eu estava em casa de minha avó". N. G. V., 6 anos, sexo feminino, leucoderma, aluna do J. d. I. do Grupo J. Barbalho. Seu pai é funcionário pública e sua mãe cuida da casa. Tem quatro irmãos mais velhos e três irmãos mais moços. A família é da classe média e reside à rua Bela Vista. Vizinhos da mesma condição social. A paciente brinca com seus irmãos e vizinhos. E alvo de atençõus especiais por parte da aró (Ficha 155).

Sonho - real e recente: "Eu outro dia sonhei que minha tia que se chama Nicinha e meu tio que se chama José Lourenço veio do Rio de Janeiro" L. O. M. R., 5 anos, sexo masculino, leucodermo, aluno do J. d. I. do Grupo J. Barbalho. Seu pai é médico e sua mãe cuida do lar. Moram junto à residência dos avós 
e tios maternos, à rua 7 de Setembro. Sua família é abastada e os vizinhos igualmente. Tem uma irmã mais moça. Brinca com a irmã e com algumas crianças vizinhas, e é objeto de especial estima por parte dos seus tios e vizinhos (Ficha 106).

Sonho - "Sonhei com meu tio... êle é marinheiro... eu ia no dêle. Sonhei com minha tia $e$ minha avó que ia para todo o canto comigo... Vovó ia me levar para Campina... ela mora lá... êle todo o dia ia me levar para o navio... eu gostava". D. A. C., 6 anos, sexo feminino, leucoderma, aluna do J. d. I. do Inst. Pedagógico. Seu pai é pedreiro e sua mãe costureira. Tem quatro irmãos mais velhos e dois mais moços. Sua família é modesta e mora no Córrego do Bartolomeu. Seus vizinhos são de condição econômica inferior. Mimada pela avó e peio tio (Ficha 76).

Sonho - "Sonhei que ia na casa de Tio... brincava com os meninos de corda, de pega..." "Z. R. de F. N., 5 anos, sexo feminino, leucoderma, aluna do J. d. I. do Inst. Pedagógico. Seu pai é funcionário público e sua mãe cuida da casa. A família é modesta e reside à rua $G$ Vila Popular. Tem três irmãs mais velhas e um mais moço. Os vizinhọs são da mesma condição econômica. E mimađa pelo tio, em cuja casa lhe dão atenções especiais (Ficha 70).

Doze crianças, residentes na zona suburbana, ajustadas na sua ambiência, convivendo com outras crianças da mesma idade, e cujos brinquedos giram em tôrno de animais domésticos (brinquedos de meninos influenciados pela zona rural e em mais contacto com a natureza: cavalos de pau, bois de barro, carneirinhos, etc.), sêres que lhes despertam interêsse de posse e de novas experiências que se desenroiam à sua presença, relataram sonhos de relatividade lógica num misto de fatos e emoções ligadas à vida campestre e possíveis em estado de vigília, outros de simbólica simples onde animais surgem apenas como expressão de fôrça e poder, mas não atemorizantes (Fichas 108, 80, 75, 52, 41, 33, 31, 15, 100, 99, 98, 94). Enquanto crianças da zona urbana, em número de dez, contaram sonhos em que animais surgem como símbolos de temor e mesmo aterrorizantes: "uma barata que vinha roer o menino", "um camelo debaixo da cama me mordendo...", "um sapo que ainha mijar no men ôlho", "um touro me mordendo, que é isso meu Deus?", "um bezouro que vinha me pegar", "uma vaca que vinha me comer", "um rato que vinha me roer", "um bicho que vinha prá minha cama", "um bicho me mordendo na cama", "uma vaca que vinha me pegar". Uma indagação sumária evidenciou o hábito, por parte dos seus pais, de lhes fazer mêdo para obter uma norma de conduta, verificando-se que estas dez crianças eram objeto de temores associados e condicionados: "Se não fôr dormir agora vem um bicho e the pega...", "se não ficar quieto vem um bicho e the morde...", etc. Animais pacíficos e inofensivos são utilizados para a forma perniciosa de intimidação, fixando ideações penosas e atormentadoras (Fichas 96, 151, 73, 67, 64, 53, 101, 97, $95,86)$. 
Um sonho de assombração em que o agente causador (a avó) useiro em atitudes de atemorização em tôrno do escuro (quarto escuro...), surge em plena ação malfazeja, mas impessoalmente (não seria a sua avó, mas uma avó dum menino... - na realidade ela própria) foi contado por um menino de 6 anos, pleno de riqueza imaginativa, uma como miniatura de conto "à la Hoffman":

Sonho - real: "Eu estava na calçada d meia-noite... um menino $e$ com a mãe $e$ eu seguro no velocipede... $e$ a avó do menino embrulhando com papel de sêda uma porção de vela... as velas em cima da mesa e um bocado derretida no chäo... eu estava dentro do quarto estava escuro... e a luz apagada... eu estava dentro do quarto $e$ eu abria os olhos quando o clareio apagou-se e vi uma cara tão feia!" J. C. de F., 6 anos, sexo masculino, leucodermo, aluno do J. d. I. do Grupo S. Campos. Seu pai é alfaiate e sua mãe cuida da casa. Tem um irmão mais moço. A sua família é modesta e mora à Praça Siqueira Campos. Os vizinhos são da mesma condição social. O paciente só brinca dentro de casa. (Ficha 22).

O drama afetivo da perda da posição de caçula com o nascimento dum outro irmão que surgiu como um novo coletor de carinhos, agravado com o descaso dos pais em tôrno dêsse problema infantil, a ponto de entregar o "reizinho destronado" aos cuidados duma empregada descuidada e até mesmo hostil, surge no sonho relatado por um menino de 6 anos:

Sonho - real: "Eu sonhei que o bonde cortou a perna do meu irmão... (o paciente mostra-se impressionado co contar o sonho) sonhei também com uma coisa preta que ia subindo pela minha cama e ai eu ouvi um barulho com a fala de papai certinha $e$ ai eu me acordei". R. F. M., 6 anos, sexo masculino, leucodermo, aluno do J. d. I. do Grupo J. Barbalho. Seu pai é funcionário federal e sua mãe cuida do lar. Tem cinco irmãos mais velhos e um irmão mais moço. Sua família é de condição social modesta e mora à rua do Jasmim. O paciente acha que os vizinhos são ricos, mais do que seu pai. Brinca com irmãos mais velhos e algumas crianças vizinhas. $R$. conta que o quintal da sua casa é muito escuro à noite e que a sua empregada (negra) the faz mêdo, pregando-lhe sustos, e que não gosta dela porque ela é muito ruim, e que por isso procura às vêzes torcer o braço dela (Ficha 103).

Outro menino de 6 anos, aluno de J.d.I. do Grupo A. de Medeiros, "preterido" pelo nascimento duma irmã, sonha que "mamãe tinha um menino... ela teve uma dor... foi prá Assistência..." (Ficha 63).

$\mathrm{O}$ sentimento de inferioridade condicionado à situação feminil e inferioridade de órgãos en face dos seus colegas do sexo oposto e dominante, surge num sonho eivado de símbolos de mutilação, duma menina de 7 anos:

Sonho - real: "Sonhei que arranquei un dente... botei a bacia $e$ botei $o$ dente dentro da água da bacia... arranquei também meu braço... porque mamãe se cansou... me levou e eu chorei... só’". A. A. do N., 7 anos, sexo feminino, leucoderma, aluna do J. d. I. do Inst. Pedagógico. Seu pai é motorista e sua mãe 
cuida da casa. Tem uma irmã mais velha, de 8 anos, e a família é de condição modesta. Mora à rua Dantas. Seus vizinhos são da mesma condição social (Ficha 82).

Sete crianças relataram sonhos de morte. Dois meninos de 6 anos, cujos pais faleceram, expressaram nos seus sonhos sua posição em face do genitor.

Um que o tinha como protótipo apresenta-se com o seu sentimento de inferioridade agravado por esta perda e sonha com o pai vivo, abraçando-o (Ficha 42). O outro, igualmente com 6 anos, com intensa projeção afetiva pela genitora, sente-o, no sonho, ao contrário, voltando à vida para matá-lo ("Sonhei que pai estava vivo... que êle queria matar eu... eu chamava mãe..." (Ficha 81), ainda temeroso das regalias paternas, do mais vantajoso rival do seu afeto. As cinco outras, tendo os genitores vivos, sonham com a morte de um dêles:

V., de 5 anos, sexo feminino, aluna do J. d. I. do Grupo J. Barbalho, com carga afetiva dirigida para o pai, sonha com a morte de sua mãe (Ficha 156); E., de 6 anos, sexo masculino, aluno do J. d. I. do Inst. Pedagógico, e em situação inversa "sonha com um homem morrendo $e$ um bocado de flor $e$ um caixão... sòmente" (Ficha 68); L. de 5 anos, sexo feminino, aluna "difícil" do J. d. I. do Inst. Pedagógico, filha única entre irmãos do sexo masculino e mais velhos, sonha o extermínio de tôda a sua família: "sonhei um soldado matando com bala mãe, pai, Edinho e Berto, Lucilo...e eu" [sentimento de inferioridade de órgãos ante os irmãos, projeção de afeto aos pais, os "maiores", introjeção e sentimento culposo (Ficha 69)]; e duas outras intensamente trabalhadas por mal orientado proselitismo religioso, onde a vida imaterial é fixada como situação mais vantajosa que a terrena, sonlam: "Foi que morri $\mathcal{c}$ estara $e$ a minha alma foi para o céu", F., 6 anos, sexo masculino, aluno do J. d. I. do Grupo J. Barbalho, tem uma irmã mais velha, mora num primeiro andar, não brinca com outras crianças (Ficha 111); "Eu sonhei que morri, que mamãe morreu e ai eu morria também... e minha irmã morrcu $\mathcal{C}$ todo mundo morreu $\mathcal{c}$ assistência vein,

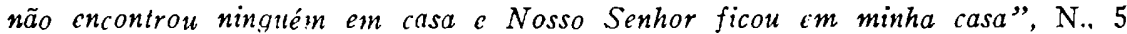
anos, sexo masculino, aluno de J. d. I. do Grupo J. Barbalho, tem sete irmãos mais velhos, não brinca com os vizinhos "porque êles não prestam, só brincam de porcarias".

Quatro crianças, dois meninos de 5 e 6 anos, e duas meninas de 4 e 5 anos, contaram sonhos de participação do leito dos pais, com referência particular a um dos genitores do sexo oposto:

"Foi com papai.. assim dormindo...", -M., 5 anos, sexo feminino, aluna do J. d. I. do Grupo J. Barbalho, quatro irmãos mais velhos e dois mais moços, filha única entre irmãos do sexo masculin», família abastada (Ficha 152) ; "Eu fui dormir com mamãe... aí veio um vulto por cima da casa sacudindo pedra em mim e na minha mãe", A., 6 anos, sexo masculino, aluno do J. d. I. do Grupo A. de Medeiros, tem três irmãos e duas irmãs mais velhos, "caçula" de família modesta (Ficha 61) ; "Eu sonhei na cama... e papai tirou eu da cama (dêle) ". E., 4 anos, sexo masculino, aluno do J. d. I. do Grupo J. Barbalho, tem dois irmãos e uma irmã mais velhos e um mais moço (Ficha 102); "Sonhei na cama com pai", T., 4 anos, sexo feminino, aluna do J. d. I. do Grupo A. de Medeiros, tem quatro irmãos mais velhos e uma irmã mais moça (Ficha 32).

Uma menina de 5 anos, órfã de mãe, e menina única entre irmãos, com os quais brinca de maneiia masculina, relata um sonho "dormindo com uma irmã " 
(ela própria), ficha 154; enquanto um menino da mesma idade, mais moço entre quatto irmãos, sem convivência com outras crianças da vizinhança, conta que "sonhou com um dos irmãos na cama enquanto a mãe andava em um bocado de avião roncando" (fantasias sôbre o poder paterno nas suas relações?) ficha 104.

\section{RESUMO}

O autor procurou realizar um reconhecimento do comportamento familiar e sua influência na formação do estilo de vida da criança, analisando sonhos de alunos dos jardins de infância de escolas públicas. As correlações entre o material colhido e a conduta parental em face da criança, aferidas à medida que se processava a pesquisa, fazem acreditar ser êste um meio utilizável pelo educador especializado para sondar as normas e atitudes da família diante do escolar, na vida doméstica.

$$
\text { Rua Conde de Boa Vista, } 829 \text { - Pernambuco - Brasil. }
$$

